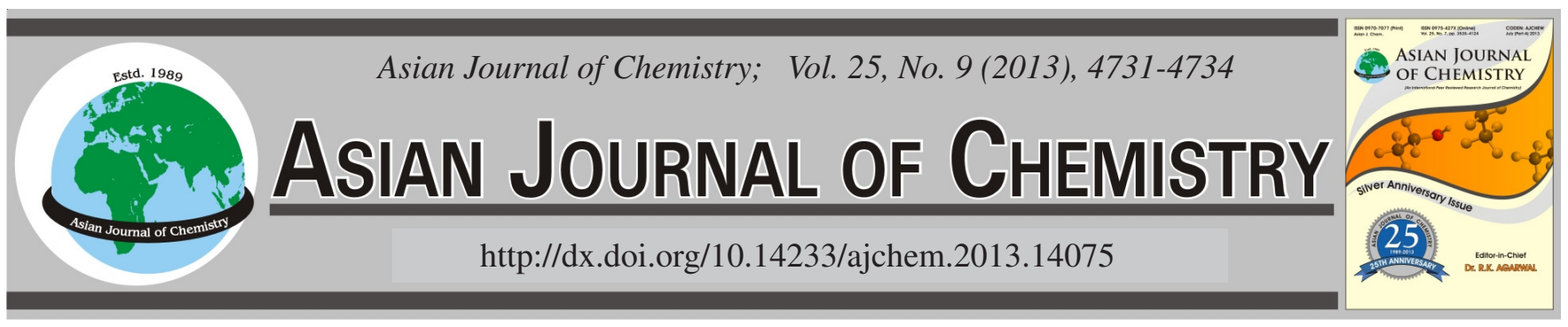

\title{
Thermodynamic Study of Chemiluminescent Reactions
}

\section{Zhenhua MeI ${ }^{1, *}$, Shuyu $\mathrm{MeI}^{2}$ and Xu Hun ${ }^{3}$}

${ }^{1}$ State Key Laboratory Base of Eco-chemical Engineering, College of Chemistry and Molecular Engineering, Qingdao University of Science and Technology, Qingdao 266042, P.R. China

${ }^{2}$ Medical College, Qingdao University, Qingdao 266071, Shandong Province, P.R. China

${ }^{3}$ College of Chemistry and Molecular Engineering, Qingdao University of Science and Technology, Qingdao 266042, P.R. China

*Corresponding author: Tel./Fax: +86 532 84022681; E-mail: mzh62@qust.edu.cn

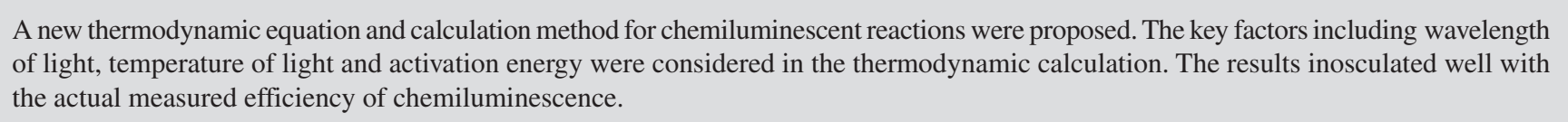

Key Words: Thermodynamic, Chemiluminescence, Physical chemistry.

\section{INTRODUCTION}

Chemiluminescence is a typical type of chemical reaction. Its chemical reaction heat emits in the form of visible light not heat radiation. The chemiluminescent reactions must follow all the thermodynamic laws. There were some early reports concerned with the behaviours of chemiluminescence in thermodynamics ${ }^{1-6}$; therein Wilson has done useful work in his paper ${ }^{1}$. As the case may be, a problem that leaved behind, is necessary to be solved and give it a more clearly discussion or explanation in thermodynamics.

In this paper, the discussion of chemiluminescent thermodynamics were developed with the consideration of the wavelength of light, the temperature of light, the activation energy and irreversible light absorption of surroundings.

\section{EXPERIMENTAL}

Temperature of light: The concept-temperature of light, has no actual meaning. It induced here to show the light temperature which corresponding the radiation of a blackbody. The radiation density of a blackbody has a characteristically continuous distribution along wavelength at any given temperature, according to Planck distribution law of blackbody radiation. Therefore, there must exist a photon (with a characterized wavelength) that corresponding to the average energy of a photon, i.e., the representative wavelength $\left(\lambda_{\text {aver }}\right)$ of average energy. Thus, according to Planck distribution law $\rho(\mathrm{T}, \lambda)=8 \pi \mathrm{hc} \lambda^{-5}\left[\exp \left(\mathrm{hck}^{-1} \mathrm{~T}^{-1} \lambda^{-1}\right)^{-1}\right]^{-1}$, we obtain the equation as follows:

$$
\lambda_{\text {aver E }}=\frac{\int_{10}^{7000} \rho(\lambda, T) \mathrm{d} \lambda}{\int_{10}^{7000} \lambda^{-1}(\lambda, T) \mathrm{d} \lambda}
$$

Drawing the curve of $\rho(T, \lambda)$ and $\lambda^{-1} \rho(T, \lambda)$ to $\lambda$ at pointed temperature (as an example showed in Figs. 1 and 2 at 4000 $\mathrm{K})$, by the using of graphic method, the areas under their curves were obtained. The areas were the answer of $\int_{10}^{7000} \rho(\lambda, T) d \lambda$ and $\int_{10}^{7000} \lambda^{-1}(\lambda, \mathrm{T}) \mathrm{d} \lambda$. Then at temperature 4000, 6000 and $8000 \mathrm{~K}$, the representative wavelength of average energy- $\lambda_{\text {aver E }}$ were obtained to be $898.26,598.68$ and $448.94 \mathrm{~nm}$, respectively; the values of $\lambda_{\text {aver E }} \mathrm{T}$ were to be 3593040,3592080 and $3591520 \mathrm{~nm} \mathrm{~K}$. It shows that $\mathrm{T} \lambda_{\text {aver E }}$ to be a constant at an average value of $3592213 \mathrm{~nm} \mathrm{~K}$, i.e., the significant figure of $3.592 \times 10^{6} \mathrm{~nm} \mathrm{~K}$. Thus, we obtained the following:

$\lambda_{\text {aver E }} \mathrm{T} \approx 3.592 \times 10^{6} \mathrm{~nm} \mathrm{~K}=1.239 \times 2.898 \times 10^{6} \mathrm{~nm}$

$$
\begin{aligned}
\mathrm{K} & =1.239 \lambda_{\max } \mathrm{T} \\
\lambda_{\text {aver E }} & =1.239 \lambda_{\max }
\end{aligned}
$$

where, $\lambda_{\max }$ stood for the wavelength of maximal radiation of a blackbody.

Activation energy and release energy: Every chemical reaction system has its own activation energy i.e., $\mathrm{E}_{\mathrm{a}}$. Most of them have positive values. The chemical reaction takes place only if the one-off collision energy of molecules is over its activation energy. The activation energy is supplied by surroundings of the chemical reaction, i.e., this is a heat absorption process (the first process). For the standard variation of 


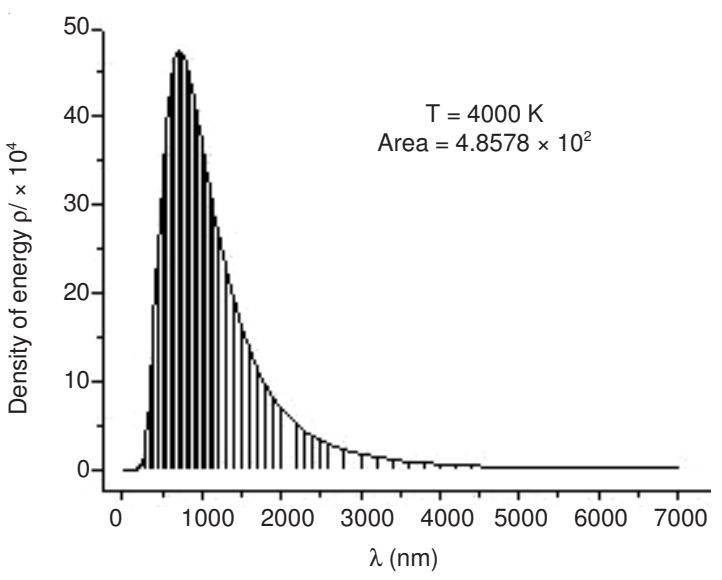

Fig. 1. Curve of $\rho(T, \lambda)$ varying with $\lambda$

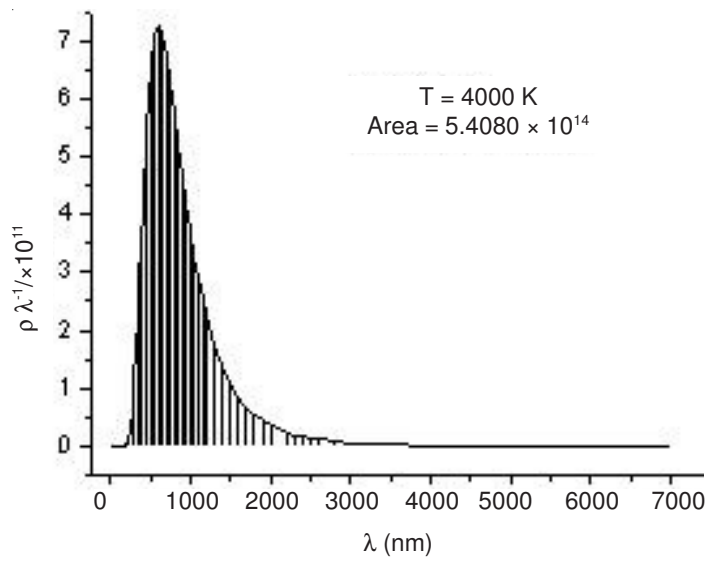

Fig. 2. Curve of $\lambda-1 \rho(\mathrm{T}, \lambda)$ varying with $\lambda$

enthalpy, $\Delta_{\mathrm{r}} \mathrm{H}_{\mathrm{m}}^{\theta}$ is the net variation of heat absorption of the reaction (at constant pressure), the second process after activated complexes state is a energy release process which can calculated by

$$
\mathrm{E}_{\text {release }}=\Delta_{\mathrm{r}} \mathrm{H}_{\mathrm{m}}^{\theta}-\mathrm{E}_{\mathrm{a}}
$$

To most normal chemical reactions, the absorption energy (first process) and the release energy (second process) has the same heat radiation form. However, to chemiluminescent reactions, they are different, one is in heat radiation form and another is in visible light.

For the absence of $E_{a}$ of following discussed chemiluminescent reactions, a roughly theoretical Hirschfelder calculation formula $\mathrm{E}_{\mathrm{a}}=0.055 \mathrm{D}_{\mathrm{A}-\mathrm{B}}$ was used instead ${ }^{7}$, where $\mathrm{D}_{\mathrm{A}-\mathrm{B}}$ is dissociated energy between atom A and B. The results were listed in Table-1 and represented with $\mathrm{E}_{\mathrm{a}}$.

Chemiluminescent reactions and thermodynamic data: Several typical chemiluminescent reactions were collected under consideration. They were lominol, peroxyoxalate, ethylene, $\mathrm{NO}, \mathrm{CO}$ and $\mathrm{SO}_{2}$ etc., reagents reacted with oxidant. Their thermochemical equations were expressed as follows:

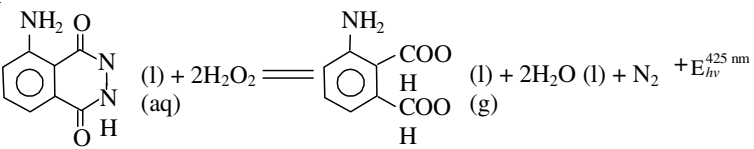

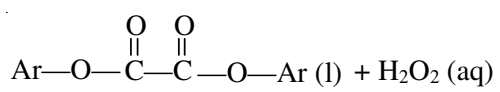

$$
\begin{aligned}
& =2 \mathrm{CO}_{2}(\mathrm{~g})+2 \mathrm{ArOH}(\mathrm{l})+\mathrm{E}_{h v}^{55 \mathrm{~nm}} \\
& \mathrm{NO}(\mathrm{g})+\mathrm{O}_{3}(\mathrm{~g}) \rightarrow \mathrm{NO}_{2} *(\mathrm{~g})+\mathrm{O}_{2}(\mathrm{~g}) \rightarrow \\
& \mathrm{NO}_{2}(\mathrm{~g})+\mathrm{O}_{2}(\mathrm{~g})+\mathrm{E}_{\mathrm{hv}}^{737 \mathrm{~nm}} \\
& \mathrm{SO}_{2}(\mathrm{~g})+2 \mathrm{O}(\mathrm{g}) \rightarrow \mathrm{SO}_{2} *(\mathrm{~g})+\mathrm{O}_{2}(\mathrm{~g}) \rightarrow \\
& \mathrm{SO}_{2}(\mathrm{~g})+\mathrm{O}_{2}(\mathrm{~g})+\mathrm{E}_{\mathrm{hv}}^{200 \mathrm{~nm}} \\
& \mathrm{NO}(\mathrm{g})+\mathrm{O}(\mathrm{g}) \rightarrow \mathrm{NO}_{2} *(\mathrm{~g}) \rightarrow \mathrm{NO}_{2}(\mathrm{~g})+\mathrm{E}_{\mathrm{hv}}^{900 \mathrm{~nm}} \\
& \mathrm{H}_{2} \mathrm{C}=\mathrm{CH}_{2}(\mathrm{~g})+\mathrm{O}_{3}(\mathrm{~g}) \rightarrow \mathrm{HCOOH}+\mathrm{CH}_{2} \mathrm{O} * \rightarrow \mathrm{HCOOH}(\mathrm{l}) \\
& +\mathrm{CH}_{2} \mathrm{O}(\mathrm{g})+\mathrm{E}_{\mathrm{hv}}^{435 \mathrm{~nm}} \\
& \mathrm{CO}(\mathrm{g})+\mathrm{O}(\mathrm{g}) \rightarrow \mathrm{CO}_{2} *(\mathrm{~g}) \rightarrow \mathrm{CO}_{2}(\mathrm{~g})+\mathrm{E}_{\mathrm{hv}}^{400 \mathrm{~nm}}
\end{aligned}
$$

Their related thermodynamic calculating data were shown in Table-1. The supporting basic data ${ }^{8,9}$ of thermodynamics of the reactants and resultants were listed in Table- 2 .

\section{RESULTS AND DISCUSSION}

Calculation of equilibrium constant $\mathrm{K}^{\boldsymbol{\theta}}$ : General thermodynamic calculation of equilibrium constant $\mathrm{K}^{\theta}$ is according to the well-known thermodynamic formulas:

$$
\begin{gathered}
\Delta_{\mathrm{r}} \mathrm{G}_{\mathrm{m}}^{\theta}=\Delta_{\mathrm{r}} \mathrm{H}_{\mathrm{m}}^{\theta}-\mathrm{T} \Delta_{\mathrm{r}} \mathrm{S}_{\mathrm{m}}^{\theta} \\
\Delta_{\mathrm{r}} \mathrm{G}_{\mathrm{m}}^{\theta}=-\mathrm{RT} \ln \mathrm{K}^{\theta}
\end{gathered}
$$

\begin{tabular}{|c|c|c|c|c|c|c|c|c|}
\hline $\begin{array}{c}\text { Chemical equation } \\
\text { number }\end{array}$ & $\mathrm{E}_{\mathrm{a}}\left(\mathrm{kJ} \mathrm{mol}^{-1}\right)$ & $\begin{array}{c}\Delta_{\mathrm{r}} \mathrm{H}_{\mathrm{m}}{ }^{\theta} \\
\left(\mathrm{kJ} \mathrm{mol}^{-1}\right)\end{array}$ & $\begin{array}{c}\Delta_{\mathrm{r}} \mathrm{S}_{\mathrm{m}}{ }^{\theta} \\
\left(\mathrm{J} \mathrm{mol}^{-1}\right)\end{array}$ & $\begin{array}{c}\mathrm{K}_{1}^{\theta} \\
\text { (troditional) }\end{array}$ & $\begin{array}{c}\alpha_{1}(\%) \\
\text { (troditional) }\end{array}$ & $\begin{array}{c}\mathrm{K}_{2}^{\theta} \\
\text { (current) }\end{array}$ & $\begin{array}{c}\alpha_{2}(\%) \\
\text { (current) }\end{array}$ & $\begin{array}{c}\Phi \\
(\%)\end{array}$ \\
\hline (4) & 16.8 & -737.4 & -84.52 & $3.1 \times 10^{126}$ & 100 & $2.0 \times 10^{-3}$ & 1.8 & 1.5 \\
\hline (5) & 19.6 & -381.9 & +323.3 & $5.6 \times 10^{83}$ & 100 & $4.7 \times 10^{16}$ & 100 & 37 \\
\hline (6) & 22.2 & -199.8 & -4.5 .0 & $5.8 \times 10^{34}$ & 100 & $1.8 \times 10^{-2}$ & 11.8 & 10 \\
\hline (7) & 0 & -498.3 & -117.1 & $1.5 \times 10^{81}$ & 100 & $2.1 \times 10^{-5}$ & 0.21 & - \\
\hline (8) & 8.25 & -306.2 & -131.8 & $5.9 \times 10^{46}$ & 100 & $6.1 \times 10^{-5}$ & 0.60 & - \\
\hline (9) & 33.8 & -728.2 & -110.6 & $6.3 \times 10^{121}$ & 100 & $1.3 \times 10^{-7}$ & 0.001 & - \\
\hline (10) & 19.8 & -532.1 & -145.1 & $4.4 \times 10^{85}$ & 100 & $1.4 \times 10^{-8}$ & 0.0001 & - \\
\hline
\end{tabular}

However, they cannot be used here for chemiluminescent reactions because it requires a promise that the released heat energy of chemical reaction absorbed by its surroundings is to be reversible process in the formula deducing of free energy. Now, the situations changed. To chemiluminescent reactions, the released energy is mainly in the form of visible light. Therefore, the surroundings absorb visible light is an irreversible process at a normal temperature. We cannot use eqns. 11 and 12; their extortion use would result in a wrong

TABLE-1

RELATED THERMODYNAMIC DATA FOR SELECTED CHEMILUMINESCENT REACTIONS

$\Phi$ represent the actually measured data of luminescence efficiency; $\mathrm{K}^{\theta}$ is the standard equilibrium constant and $\alpha$ the conversion factor at equilibrium state; $\mathrm{K}_{1}^{\theta}, \alpha_{1}$ were the calculated results by traditional method; $\mathrm{K}^{\theta}{ }_{2}, \alpha_{2}$ were that by current calculating method. 
TABLE-2

THERMODYNAMIC DATA OF THE REACTANTS AND RESULTANTS

\begin{tabular}{|c|c|c|c|c|c|c|c|c|}
\hline Compound & $\begin{array}{c}\Delta_{\mathrm{f}} \mathrm{H}_{\mathrm{m}}{ }^{\theta} \\
\left(\mathrm{kJ} \mathrm{mol}^{-1}\right)\end{array}$ & $\begin{array}{c}\Delta_{\mathrm{f}} \mathrm{S}_{\mathrm{m}}{ }^{\theta} \\
\left(\mathrm{J} \mathrm{mol}^{-1}\right)\end{array}$ & Compound & $\begin{array}{c}\Delta_{\mathrm{f}} \mathrm{H}_{\mathrm{m}}{ }^{\theta} \\
\left(\mathrm{kJ} \mathrm{mol}^{-1}\right)\end{array}$ & $\begin{array}{c}\Delta_{\mathrm{f}} \mathrm{S}_{\mathrm{m}}{ }^{\theta} \\
\left(\mathrm{J} \mathrm{mol}^{-1}\right)\end{array}$ & Compound & $\begin{array}{c}\Delta_{\mathrm{f}} \mathrm{H}_{\mathrm{m}}{ }^{\theta} \\
\left(\mathrm{kJ} \mathrm{mol}^{-1}\right)\end{array}$ & $\begin{array}{c}\Delta_{\mathrm{f}} \mathrm{S}_{\mathrm{m}}{ }^{\theta} \\
\left(\mathrm{J} \mathrm{mol}^{-1}\right)\end{array}$ \\
\hline $\mathrm{R}_{\text {Lominol }}(1)$ & $-288.3^{a}$ & $410.5^{*}$ & $\mathrm{R}_{\text {Peroxyo. }}(\mathrm{l})$ & $-528.3^{*}$ & $331.9^{*}$ & $\mathrm{H}_{2} \mathrm{O}(\mathrm{l})$ & -285.8 & 69.94 \\
\hline $\mathrm{O}_{\text {Lominol }}(\mathrm{l})$ & $-836.5^{*}$ & $282.6^{*}$ & $\mathrm{O}_{\text {Peroxyo. }}(1)$ & $-157.2^{*}$ & $186.0^{*}$ & $\mathrm{H}_{2} \mathrm{O}_{2}(\mathrm{aq})$ & -191.2 & 144.0 \\
\hline $\mathrm{C}_{2} \mathrm{H}_{4}(\mathrm{~g})$ & 52.26 & 219.5 & $\mathrm{CH}_{2} \mathrm{O}(\mathrm{g})$ & -108.5 & 218.8 & $\mathrm{O}_{2}(\mathrm{~g})$ & 0 & 205.1 \\
\hline $\mathrm{HCOOH}(1)$ & -424.7 & 129.0 & $\mathrm{NO}(\mathrm{g})$ & 90.25 & 210.8 & $\mathrm{O}_{3}(\mathrm{~g})$ & 142.7 & 238.9 \\
\hline $\mathrm{N}_{2}(\mathrm{~g})$ & 0 & 191.5 & $\mathrm{NO}_{2}(\mathrm{~g})$ & 33.18 & 240.1 & $\mathrm{O}(\mathrm{g})$ & 249.2 & 161.1 \\
\hline $\mathrm{CO}(\mathrm{g})$ & -110.5 & 197.7 & $\mathrm{CO}_{2}(\mathrm{~g})$ & -393.5 & 213.7 & $\mathrm{SO}_{2}(\mathrm{~g})$ & -296.8 & 248.2 \\
\hline
\end{tabular}

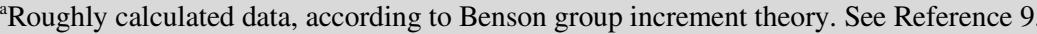

way (these extorted results as it had done, as a contrast, were listed in Table- 1 dominated by $\mathrm{K}_{1}^{\theta}$ and $\alpha_{1}$ ). Well then, how can we do?

Formula (11) and (12) can be rewrite as:

$$
\begin{gathered}
\Delta_{\mathrm{r}} \mathrm{H}_{\mathrm{m}}^{\theta}-\mathrm{T} \Delta_{\mathrm{r}} \mathrm{S}_{\mathrm{m}}^{\theta}=-\mathrm{RT} \ln \mathrm{K}^{\theta} \\
\ln \mathrm{K}^{\theta}=\mathrm{R}^{-1}\left(\Delta_{\mathrm{r}} \mathrm{S}_{\mathrm{m}}^{\theta}-\Delta_{\mathrm{r}} \mathrm{H}_{\mathrm{m}}^{\theta} \mathrm{T}^{-1}\right)=\mathrm{R}^{-1}\left(\Delta_{\mathrm{r}} \mathrm{S}_{\mathrm{m}}^{\theta}-\mathrm{QT}^{-1}\right) \\
=\mathrm{R}^{-1}\left(\Delta_{\mathrm{r}} \mathrm{S}_{\mathrm{m}}^{\theta}+\Delta_{\mathrm{s}} \mathrm{S}_{\mathrm{m}}^{\theta}\right)=\Delta_{\mathrm{i}} \mathrm{S}_{\mathrm{m}}^{\theta} / \mathrm{R}
\end{gathered}
$$

Therefore, we obtained relationship

$$
\mathrm{K}^{\theta}=\exp \left(\frac{\Delta_{\mathrm{r}} \mathrm{S}_{\mathrm{m}}^{\theta}}{\mathrm{R}}\right)
$$

where, $\Delta_{\mathrm{s}} \mathrm{S}_{\mathrm{m}}^{\theta}$ stands for the variation of entropy of surroundings, $\Delta_{\mathrm{i}} \mathrm{S}_{\mathrm{m}}^{\theta}$ is the variation of entropy of an isolated system.

Although eqn. 13 was obtained from (11) and (12), we supposed it to be a universally correct formula for all chemical reactions including chemiluminescent reactions. In order to check its rationality, we take chemiluminescent reaction (4) as an example (where the wavelength of chemiluminescence is $425 \mathrm{~nm}$, i.e., $\lambda_{\text {aver } \mathrm{E}}=425 \mathrm{~nm}$ ).

As usual, we have

$$
\begin{aligned}
\Delta_{\mathrm{r}} \mathrm{H}_{\mathrm{m}}^{\theta}=-836.5+2 & \times(-285.8)+0-(-288.3)- \\
& 2 \times(-191.2)=-737.4 \mathrm{~kJ} \mathrm{~mol}^{-1} \\
\Delta_{\mathrm{r}} \mathrm{S}_{\mathrm{m}}^{\theta}=191.5+2 & \times 69.94+282.6-410.5- \\
2 & \times 144=-84.52 \mathrm{~J} \mathrm{~mol}^{-1} \mathrm{~K}^{-1}
\end{aligned}
$$

The surroundings' variation entropy contains two parts, one is the variation entropy, $\Delta_{\mathrm{s}} \mathrm{S}_{\mathrm{m}, 1}^{\theta}$, that supplies the activation energy at normal temperature $\left(\mathrm{T}_{1}=298.15 \mathrm{~K}\right)$ and the other is the variation entropy, $\Delta_{\mathrm{s}} \mathrm{S}_{\mathrm{m}, 2}^{\theta}$, that receives the release energy at correspondent high temperature $\left(\mathrm{T}_{2}\right)$.

According to eqn. 2 and Hirschfelder's calculation formula, we have

$\mathrm{T}_{2}=1.239 \times 2.898 \times 10^{6} / \lambda_{\text {aver E }}=1.239 \times 2.898 \times 10^{6} / 425=$ $8450 \mathrm{~K}$

$$
\mathrm{E}_{\mathrm{a}} \approx 0.055 \mathrm{D}_{\mathrm{A}-\mathrm{B}}=0.055 \times 305=16.8 \mathrm{~kJ} \mathrm{~mol}^{-1}
$$

So, we obtained $\Delta_{\mathrm{s}} \mathrm{S}_{\mathrm{m}, 1}^{\theta}$ and $\Delta_{\mathrm{s}} \mathrm{S}_{\mathrm{m}, 2}^{\theta}$ :

$\Delta_{\mathrm{s}} \mathrm{S}_{\mathrm{m}, 1}^{\theta}=\mathrm{Q} / \mathrm{T}=\left(-\mathrm{E}_{\mathrm{a}}+\eta \mathrm{E}_{\text {release }}\right) / \mathrm{T}_{1}=\left(-16.8 \times 10^{3}+0\right) / 298.15=$ $-56.3 \mathrm{~J} \mathrm{~mol}^{-1} \mathrm{~K}^{-1}$

$$
\begin{array}{r}
\Delta_{\mathrm{s}} \mathrm{S}_{\mathrm{m}, 2}^{\theta}=\mathrm{Q} / \mathrm{T}=(\eta-1) \mathrm{E}_{\text {release }} / \mathrm{T}=(1-\eta)\left(\mathrm{E}_{\mathrm{a}}-\Delta_{\mathrm{s}} \mathrm{H}_{\mathrm{m}}^{\theta}\right) / \mathrm{T}_{2} \\
=1 \times(16.8+737.4) \times 10^{3} / 8450=89.3 \mathrm{~J} \mathrm{~mol}^{-1} \mathrm{~K}^{-1}
\end{array}
$$

where $\eta$ stands for the ratio of partial released energy (in heat radiation form) to the total released energy. Here we supposed $\eta$ to be zero because of its absent value.

Thus,

$$
\begin{aligned}
\Delta_{\mathrm{i}} \mathrm{H}_{\mathrm{m}}^{\theta} & =\Delta_{\mathrm{r}} \mathrm{S}_{\mathrm{m}}^{\theta}+\Delta_{\mathrm{s}} \mathrm{S}_{\mathrm{m}, 1}^{\theta}+\Delta_{\mathrm{s}} \mathrm{S}_{\mathrm{m}, 2}^{\theta}= \\
& -84.52-56.3+89.3=-51.5 \mathrm{~J} \mathrm{~mol}^{-1} \mathrm{~K}^{-1}
\end{aligned}
$$

From eqn. 13, we got

$$
\mathrm{K}^{\theta}=\exp \left(-\frac{51.8}{8.314}\right)=2.04 \times 10^{-3}
$$

According to the obtained equilibrium constant, it is easily to calculate the conversion factor a of $\alpha$ chemical reaction in normal way. Here, the factor a was calculated to be $1.8 \%$ under the conditions of hydrogen peroxide equilibrium concentration of $1 \%$, nitrogen, $100 \mathrm{kPa}$.

As the same, the above-mentioned chemiluminescent reactions were all calculated and resulted in $\mathrm{K}^{\theta}$ and $\alpha$. They were listed in Table- 1 titled with $\mathrm{K}_{2}^{\theta}$ and $\alpha_{2}$.

The concept conversion factor $\alpha$ and luminescence efficiency $\Phi$ has a similar but different meanings to chemiluminescent reactions. The relation between them is that, if the fluorescence quenching in a chemiluminescence system is to be or nearly zero, the luminescence efficiency will equal or nearly to its maximum value $\alpha$-the conversion factor, i.e., the conversion factor is a limitation of luminescence efficiency.

The resultant data collected in Table- 1 show that many chemiluminescent reactions have restricted low luminescence efficiency except peroxyoxalate with hydrogen peroxide. The current results $\mathrm{K}_{2}^{\theta}$ and $\alpha_{2}$ inosculate with actual measured $\Phi$ well, other than the traditional data of $\mathrm{K}_{1}^{\theta}$ and $\alpha_{1}$, they gave a entirely wrong forecast. In addition, the big difference between $\alpha_{2}$ and $\Phi$ to eqn. 5 may be the biggish degrees of fluorescence quenching in this reaction system. The current calculated data $\left(\mathrm{K}_{2}^{\theta}\right.$ and $\left.\alpha_{2}\right)$ listed in Table-1 may have to some extent errors in it; that was because of the errors or absence and substitution of some thermodynamic data.

The thermodynamic study of chemiluminescent reaction in this paper can help us understanding the hypostasis of chemiluminescent reactions, designing new chemiluminescent reagent, forecasting and increasing the chemiluminescence efficiency. The new thermodynamic formula, $K^{\theta}=\exp \left(\frac{\Delta_{i} S_{m}^{\theta}}{R}\right)$, will also be fit for photochemical reactions. 


\section{ACKNOWLEDGEMENTS}

This work has been supported in part by the Nature Science Foundation of Shandong Province (No. ZR2009BM029).

\section{REFERENCES}

1. E.B. Wilson, J. Am. Chem. Soc., 98, 3387 (1976)

2. C.L. Perrin, J. Am. Chem. Soc., 97, 4419 (1975).

3. E. Lissi, J. Am. Chem. Soc., 98, 3386 (1976).
4. P. Pringsheim, J. Phys. USSR, 10, 495 (1946).

5. Yu P. Chukova, Zh. Prikl. Spektrosk, 20, 412 (1974).

6. M.A. Weinstein, J. Opt. Soc. Am., 50, 597 (1960).

7. S.W. Xia, Activation Energy and its Calculation, Higher Education Press, Beijing, edn. 1 (1993).

8. G.L. Zhao and C.D. Jin, The Estimation of Thermodynamic Data of Organic Matter, Higher Education Press, Beijing, edn. 1 (1983).

9. Y.J. Liang and Y.C. Che, Handbook of Thermodynamic Data of Inorganic Compounds, Northeastern University Press, Shenyang, edn. 1 (1993). 